\title{
Fragmentation Studies on Tetronasin by Accurate-Mass Electrospray Tandem Mass Spectrometry
}

\author{
Tatiana Fonseca, ${ }^{\dagger}$ Norberto P. Lopes, ${ }^{*}$ Paul J. Gates, and James Staunton \\ Department of Chemistry, University of Cambridge, Cambridge, United Kingdom
}

\begin{abstract}
We report here the first full fragmentation study of tetronasin 1 . Fragmentation was carried out by high-resolution ESI-CID-MS ${ }^{n}$. The formulae of the fragment ions were determined by accurate mass measurements. It is demonstrated that the fragmentation routes observed derive essentially from a first loss of water via two different mechanisms. One minor route consists of a charge remote neutral loss and the second major route occurs via the formation of a carbocation. The fragments obtained from this carbocation were produced by subsequent complex neutral eliminations and the structures were inferred, in some cases, by carbocation stability. (J Am Soc Mass Spectrom 2004, 15, 325-335) (c) 2004 American Society for Mass Spectrometry
\end{abstract}

$\mathrm{P}$ olyether ionophores are a group of natural products that distinctively possess a carboxylate group along with several tetrahydropyran or tetrahydrofuran rings. The oxygen atoms from these groups serve as ligands for the complexation of inorganic ions [1] forming stable complexes, typically with alkali and alkaline earth metal cations [2]. The metal cations are, to a degree, encapsulated by the coordinating ether and carbonyl oxygen atoms [2]. Polyethers often exhibit biological activity as antibiotics, antiparasitic, and growth promotion agents in ruminants and poultry [3]. The biological activity of these compounds is related to their strong affinity for alkali metals and their ability to solubilize and transport metals across cell membranes as either undissociated acids or neutral complexes $[2,4]$.

In recent years, the legislative demands for the analysis of veterinary antibiotic residues has increased, leading to the development and publishing of methods for the detection of drug metabolites in food [5]. Important methods for the detection of polyether ionophore residues and metabolites in a range of animal products employ HPLC-MS and LC-MS/MS [5]. This fact has prompted the present systematic investigation of the fragmentation of different polyether ionophores carried out by this group. Studies published so far are for monensin [6], and lasalocid acid [7] along with tetrona-

Published online January 15, 2004

Address reprint requests to Dr. P. J. Gates, School of Chemistry, University of Bristol, Cantock's Close, Bristol BS8 1TS, UK. E-mail: paul.gates@ bristol.ac.uk

*Also at Faculdade de Ciências Farmacêuticas de Ribeirão Preto, Universidade de São Paulo, Via do Café S/N, CEP 14.040-903, Ribeirão Preto-SP, Brazil.

tCurrent address: Institute of Cancer Research, CRUK Laboratories, Cotswold Road, Sutton, Surrey, SM2 5NG UK. sin 1 (Figure 1) which is presented in this study. A further study of salinomycin and narasin is also being undertaken [8].

Tetronasin 1 (previously known as M139603 and ICI139603) is a polyether ionophore antibiotic which was first isolated as a white crystalline solid from the aerobic fermentation of cultures of Streptomyces longisporus (NCIB11462) [3]. Comparison of tetronasin 1 with the other common polyether ionophores shows that it contains a biosynthetically rare acyl tetronic acid moiety along with a cyclohexyl group [9]. The structure of tetronasin 1 was determined crystallographically from the sodium salt of the 4-bromo-3,5-dinitrobenzoyl derivative 2 (Figure 1) [9]. It was observed that in the crystalline phase the sodium ion was hexa-coordinated through five oxygen atoms from the molecule (two of which come from the tetronic acid moiety) and a water molecule which occupies the sixth position. The sodium ion was observed to be at the center of a very distorted octahedron, with the oxygen from the C28 hydroxyl group not participating in the coordination.

The NMR studies of the conformation of tetronasin 1 in solution showed that the sodium is still at the center of a distorted octahedron of oxygen atoms with the C28 hydroxy group being hydrogen bonded to the C5 oxygen. The water molecule involved in the coordination of tetronasin with sodium was found to be hydrogen bonded at one end to the $\mathrm{C} 28$ hydroxy group and at the other to the C27 (methoxy) oxygen [10].

Tetronasin shows very high affinity for sodium cations, which normally limits mass spectrometric studies to these ions. Previous fragmentation studies [11] have shown that complementary structural data can be obtained from the analysis of protonated ions as well as 


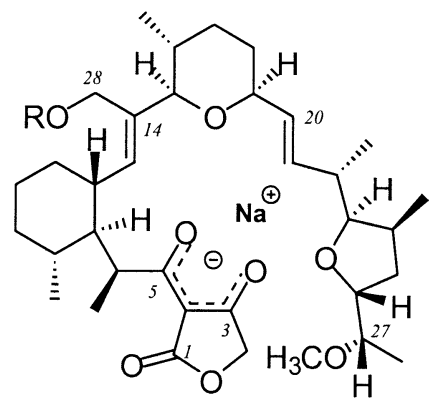

1: $\mathrm{R}=\mathrm{H}$<smiles>[Z6]P=C(C)c1cc([N+](=O)[O-])c(Br)c([N+](=O)[O-])c1</smiles>

Figure 1. The structure of tetronasin and its dinitrobenzoyl derivative.

metallated ions. The addition of ruthenium (III) chloride to ionophore solutions has been demonstrated as a highly efficient method for the generation of protonated ions [12].

In this study the main fragmentation pathways of protonated tetronasin sodium salt $[(\mathrm{M}-\mathrm{H}+\mathrm{Na})+\mathrm{H}]^{+}$ and protonated tetronasin $[(\mathrm{M}+\mathrm{H})]^{+}$are investigated using the conditions previously optimized in our laboratory [13]. The fragmentation analyses were performed on an FT-ICR instrument to produce accurate-mass data and to enable the elucidation of fragmentation routes by multistage tandem mass spectrometry $\left(\mathrm{MS}^{\mathrm{n}}\right)$.

\section{Experimental}

\section{Materials}

Methanol (HPLC grade) and ruthenium (III) chloride were obtained from Aldrich (Gillingham, UK). Deuterated water and methanol- $d_{4}$ were obtained from Fluorochem (Derbyshire, UK). Labeled water $\left(\mathrm{H}_{2}^{18} \mathrm{O} 99\right.$ atom\%) was obtained from Amersham International (Amersham, UK). Deionized water was used throughout the study. Tetronasin sodium salt was isolated from the growth of Streptomyces longisporus, through an ini-

Table 1. The masses and identities of the ions observed in the ESI mass spectrum of tetronasin

\begin{tabular}{llc}
\hline Formula & \multicolumn{1}{c}{ Identity } & $\begin{array}{c}\text { Observed } \\
\text { Mass }\end{array}$ \\
\hline \hline $\mathrm{C}_{35} \mathrm{H}_{51} \mathrm{O}_{7} \mathrm{Na}_{2}^{+}$ & {$[(\mathrm{M}-\mathrm{H}+\mathrm{Na})+\mathrm{Na}]^{+}$} & 647 \\
$\mathrm{C}_{35} \mathrm{H}_{52} \mathrm{O}_{7} \mathrm{~K}^{+}$ & {$[(\mathrm{M}-\mathrm{H}+\mathrm{K})+\mathrm{H}]^{+}$} & 641 \\
$\mathrm{C}_{35} \mathrm{H}_{50} \mathrm{O}_{6} \mathrm{Na}_{2}^{+}$ & $647^{+}-\mathrm{H}_{2} \mathrm{O}$ & 629 \\
$\mathrm{C}_{35} \mathrm{H}_{54} \mathrm{O}_{8} \mathrm{Na}^{+}$ & {$[(\mathrm{M}-\mathrm{H}+\mathrm{Na})+\mathrm{H}]^{+}$} & 625 \\
$\mathrm{C}_{35} \mathrm{H}_{52} \mathrm{O}_{7} \mathrm{Na}^{+}$ & $625^{+}-\mathrm{H}_{2} \mathrm{O}$ & 607 \\
\hline
\end{tabular}
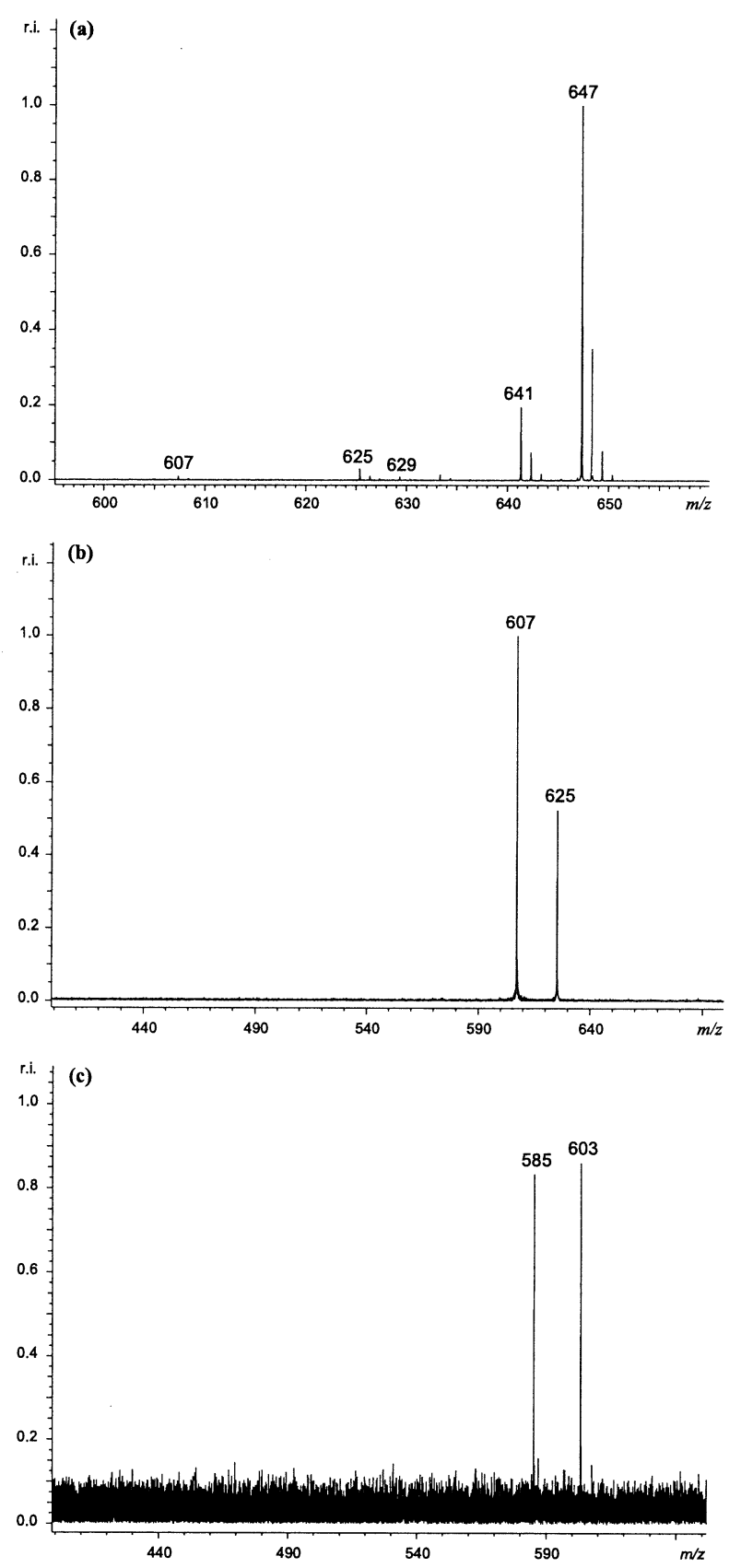

Figure 2. (a) ESI/MS spectrum of tetronasin; (b) MS/MS spectrum of $\mathrm{m} / \mathrm{z} 625$; (c) MS/MS spectrum of $\mathrm{m} / \mathrm{z} 603$.

tial methanol mycelial extraction followed by flash chromatography of the crude product using diethyl ether/light petroleum ether (1:1) as eluent to separate some of the non-polar co-metabolites until tetronasin began to be collected. The column was eluted with ethyl acetate plus $1 \%$ acetic acid to remove the remaining tetronasin [14]. For the mass spectrometry studies a stock solution of tetronasin $\left(10 \mathrm{mg} \mathrm{mL}^{-1}\right)$ was prepared in methanol and stored at $4{ }^{\circ} \mathrm{C}$. Dilute standards were prepared prior to each analysis in methanol/water (1:1) with $0.25 \mathrm{mg} \mathrm{mL}^{-1}$ as the final concentration. To generate the protonated ion of tetronasin $(\mathrm{m} / \mathrm{z}=603) 1$ 
Table 2. The formula, identity, calculated mass, observed mass, mass error, and number of incorporated ${ }^{18} \mathrm{O}$ atoms for the fragment ions observed in the $\mathrm{MS}^{3}$ spectrum of $m / z 607$ (Figure 4a).

\begin{tabular}{|c|c|c|c|c|c|}
\hline Formula & Identity & Calculated mass & Observed mass & Error (ppm) & No. of ${ }^{18} \mathrm{O}$ atoms \\
\hline $\mathrm{C}_{35} \mathrm{H}_{52} \mathrm{O}_{7} \mathrm{Na}^{+}$ & Parent Ion & 607.3605 & 607.3644 & +6.42 & \\
\hline $\mathrm{C}_{35} \mathrm{H}_{50} \mathrm{O}_{6} \mathrm{Na}^{+}$ & $607^{+}-\mathrm{H}_{2} \mathrm{O}$ & 589.3500 & 589.3476 & -4.07 & 1,2 \\
\hline $\mathrm{C}_{35} \mathrm{H}_{48} \mathrm{O}_{5} \mathrm{Na}^{+}$ & $589^{+}-\mathrm{H}_{2} \mathrm{O}$ & 571.3394 & 571.3406 & -2.10 & 1,2 \\
\hline $\mathrm{C}_{31} \mathrm{H}_{48} \mathrm{O}_{4} \mathrm{Na}^{+}$ & E3 & 507.3445 & 507.3449 & +0.79 & 1 \\
\hline $\mathrm{C}_{30} \mathrm{H}_{48} \mathrm{O}_{4} \mathrm{Na}^{+}$ & D2 & 495.3445 & 495.3450 & +1.01 & 1 \\
\hline $\mathrm{C}_{31} \mathrm{H}_{46} \mathrm{O}_{3} \mathrm{Na}^{+}$ & $\mathrm{K} 2$ & 489.3339 & 489.3347 & +1.63 & 1 \\
\hline $\mathrm{C}_{30} \mathrm{H}_{46} \mathrm{O}_{3} \mathrm{Na}^{+}$ & D3 & 477.3339 & 477.3346 & +1.47 & $0,1,2$ \\
\hline $\mathrm{C}_{27} \mathrm{H}_{36} \mathrm{O}_{4} \mathrm{Na}^{+}$ & $\mathrm{K} 1$ & 447.2506 & 447.2507 & +0.22 & 2 \\
\hline $\mathrm{C}_{21} \mathrm{H}_{28} \mathrm{O}_{5} \mathrm{Na}^{+}$ & $\mathrm{H} 1$ & 383.1829 & 383.1826 & -0.78 & 2 \\
\hline $\mathrm{C}_{21} \mathrm{H}_{26} \mathrm{O}_{4} \mathrm{Na}^{+}$ & $\mathrm{G} 3 \& \mathrm{H} 2$ & 365.1723 & 365.1711 & -3.29 & 2 \\
\hline $\mathrm{C}_{18} \mathrm{H}_{30} \mathrm{O}_{3} \mathrm{Na}^{+}$ & E2 & 317.2087 & 317.2081 & -1.89 & 0 \\
\hline $\mathrm{C}_{17} \mathrm{H}_{22} \mathrm{O}_{4} \mathrm{Na}^{+}$ & E1 & 313.1410 & 313.1407 & -0.96 & 2 \\
\hline $\mathrm{C}_{14} \mathrm{H}_{24} \mathrm{O}_{2} \mathrm{Na}^{+}$ & G4 & 247.1669 & 247.1670 & +0.40 & 0 \\
\hline & & \multicolumn{2}{|c|}{ Average error (r.m.s.) } & 1.93 & \\
\hline & & \multicolumn{2}{|c|}{ Mean residual error } & +0.23 & \\
\hline
\end{tabular}

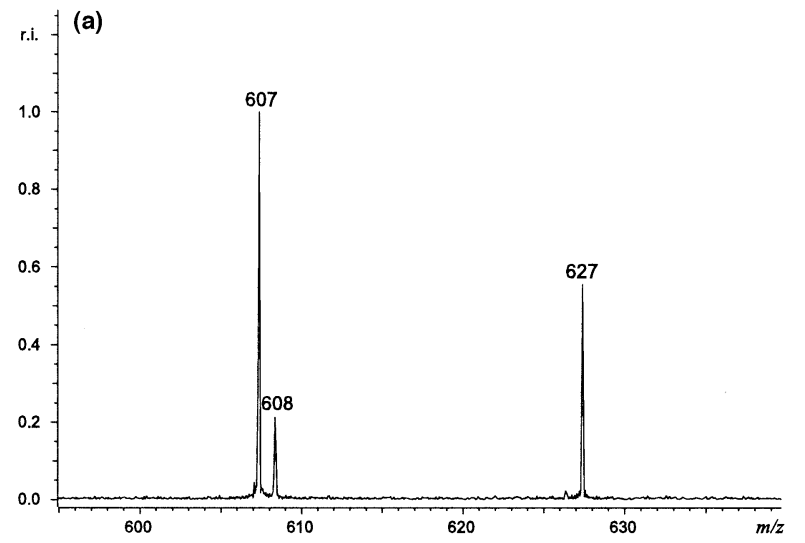

(b)

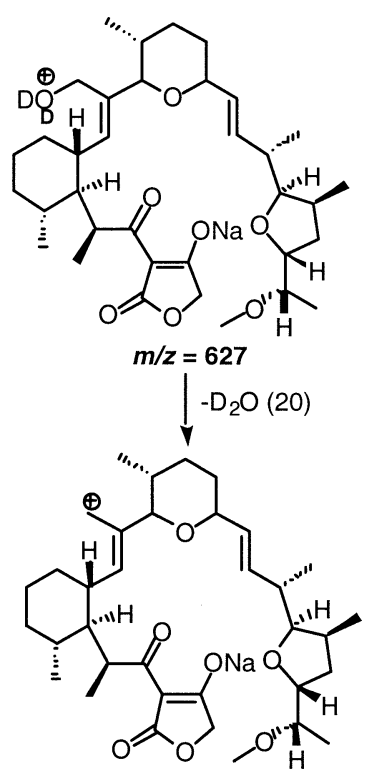

A $m / z=607$
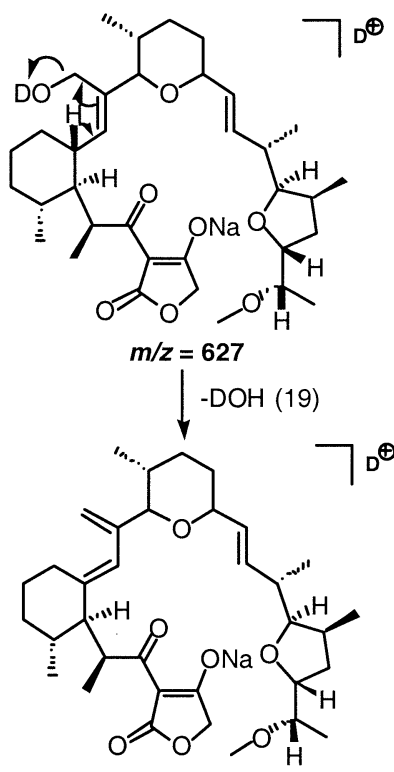

B $m / z=608$
Figure 3. (a) MS/MS spectrum of $\mathrm{m} / \mathrm{z}$ 627; (b) Two possible mechanisms for the first loss of water from the deuterated sodium salt of tetronasin $(\mathrm{m} / \mathrm{z} 627)$. equivalent of ruthenium (III) chloride was added to a solution of tetronasin and the suspension obtained was thoroughly mixed and centrifuged to separate the solid from the liquid. The supernatant was used for mass spectrometric analysis. For more details, see reference [12]. Deuteration was performed by dilution of the stock solution in $\mathrm{CD}_{3} \mathrm{OD}$ and $\mathrm{D}_{2} \mathrm{O}(1: 1)$. The solution
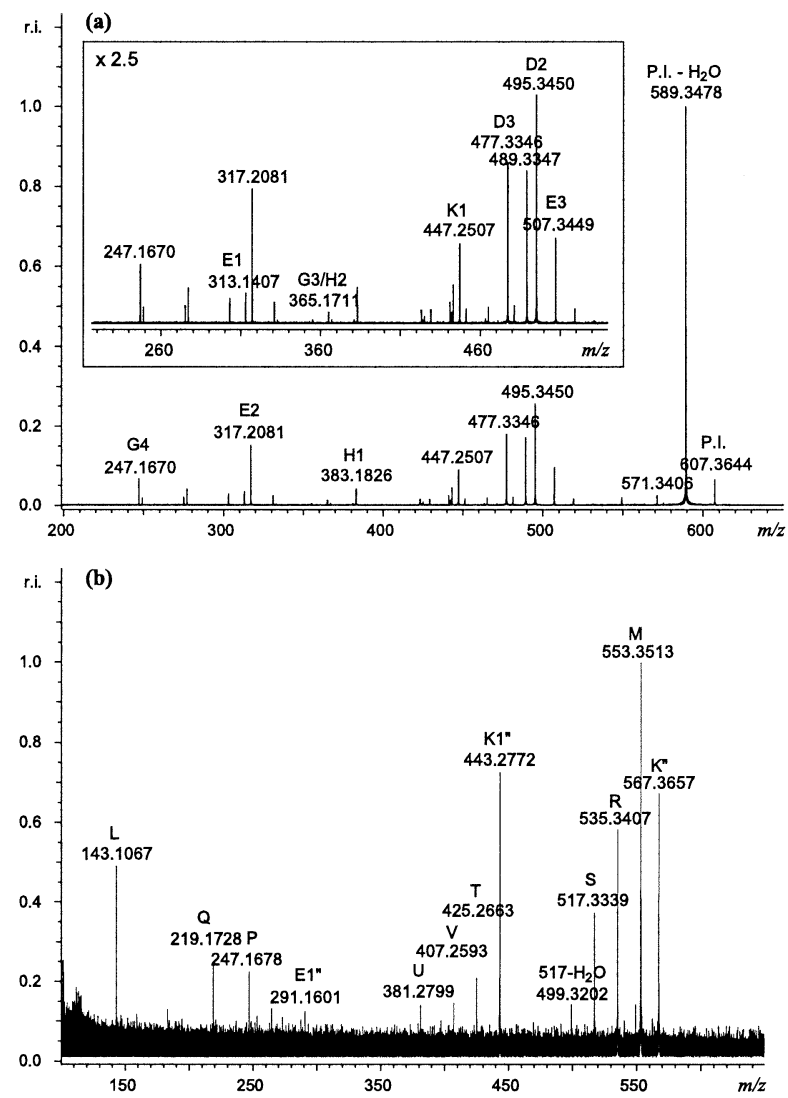

Figure 4. (a) $\mathrm{MS}^{3}$ spectrum for the protonated sodium salt of tetronasin $\left(625^{+} \rightarrow 607^{+} \rightarrow\right.$ fragments); (b) $\mathrm{MS}^{3}$ spectrum for protonated tetronasin $\left(603^{+} \rightarrow 585^{+} \rightarrow\right.$ fragments). 
(a)

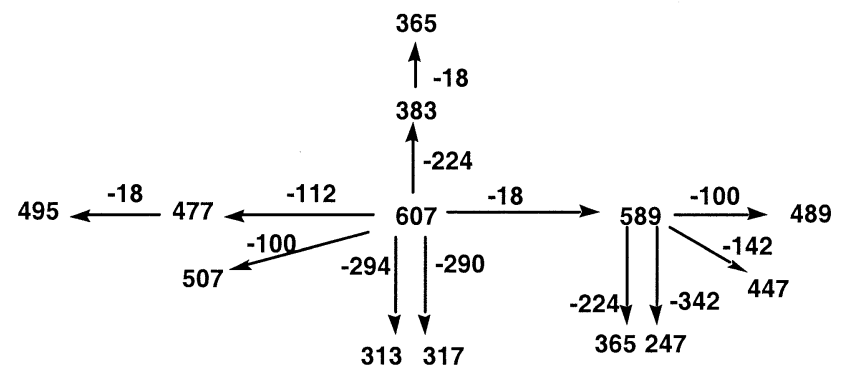

(b)

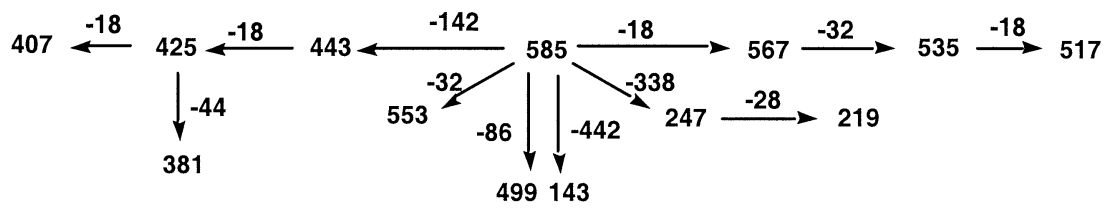

Scheme 1. (a) An overview of the $\mathrm{MS}^{3}$ fragmentation of 607 ; (b) an overview of the $\mathrm{MS}^{3}$ fragmentation of 585 .

was thoroughly mixed and all exchangeable protons were deuterated. For the ${ }^{18} \mathrm{O}$ experiments, a solution of tetronasin $\left(1 \mathrm{mg} \mathrm{mL}^{-1}\right)$ was prepared in $\mathrm{H}_{2}^{18} \mathrm{O}$, in the presence of $1 \%$ formic acid. This solution was stored refrigerated for several months to allow the carbonyl oxygen exchange to occur.

\section{Instrumentation}

Accurate-mass $\mathrm{MS}^{\mathrm{n}}$ analyses were performed on a BioApex II (4.7 tesla) Fourier-transform ion cyclotron resonance instrument (Bruker Daltonics, Billerica, MA). Solutions were infused by syringe pump through the Analytica ESI source at $100 \mu \mathrm{L} \mathrm{h}^{-1}$. Fragmentation analyses were performed on the isolated parent ions by sustained off-resonance irradiation collision induced dissociation (SORI-CID) using $\mathrm{CO}_{2}$ collision gas. Precursor ions were selectively isolated through correlated sweep isolation. The cell conditions were tuned to fragment enough of the precursor ion to observe a spectrum of good intensity across the required mass range. Sequential fragmentation steps were usually performed on optimized precursor ions from the previous step. The ESI spectra and isolation experiments were performed at a resolution of approximately 20,000. The $\mathrm{MS}^{\mathrm{n}}$ spectra had a resolution of approximately 30,000 . The mass range for the ESI experiments was from $\mathrm{m} / \mathrm{z} 100$ to 4000 and for the $\mathrm{MS}^{\mathrm{n}}$ experiments the mass range was from $\mathrm{m} / \mathrm{z} 80$ to 1000 . Usually eight individual scans were combined to produce a spectrum, but in the cases were weaker signals were observed

Table 3. The formula, identity, calculated mass, observed mass, mass error, and number of incorporated ${ }^{18} \mathrm{O}$ atoms for the fragment ions observed in the $\mathrm{MS}^{3}$ spectrum of $m / z 585$ (Figure $4 \mathrm{~b}$ ).

\begin{tabular}{|c|c|c|c|c|c|}
\hline Formula & Identity & Calculated mass & Observed mass & Error (ppm) & No. of ${ }^{18} \mathrm{O}$ atoms \\
\hline $\mathrm{C}_{35} \mathrm{H}_{53} \mathrm{O}_{7}^{+}$ & Parent lon & 585.3786 & not observed & & \\
\hline $\mathrm{C}_{35} \mathrm{H}_{51} \mathrm{O}_{6}^{+}$ & $\mathrm{K}^{\prime \prime}$ & 567.3680 & 567.3657 & -4.05 & 2 \\
\hline $\mathrm{C}_{34} \mathrm{H}_{49} \mathrm{O}_{6}^{+}$ & $\mathrm{M}$ & 553.3524 & 553.3513 & -1.99 & 2 \\
\hline $\mathrm{C}_{35} \mathrm{H}_{49} \mathrm{O}_{5}^{+}$ & $567^{+}-\mathrm{H}_{2} \mathrm{O}$ & 549.3575 & 549.3589 & +2.55 & 1 \\
\hline $\mathrm{C}_{34} \mathrm{H}_{53} \mathrm{O}_{5}^{+}$ & $\mathrm{N}$ & 541.3888 & 541.3879 & -1.66 & - \\
\hline $\mathrm{C}_{34} \mathrm{H}_{47} \mathrm{O}_{5}^{+}$ & $\mathrm{R}$ & 535.3418 & 535.3407 & -2.05 & 2 \\
\hline $\mathrm{C}_{34} \mathrm{H}_{45} \mathrm{O}_{4}^{+}$ & $\mathrm{S}$ & 517.3312 & 517.3339 & +5.22 & 1,2 \\
\hline $\mathrm{C}_{32} \mathrm{H}_{51} \mathrm{O}_{4}^{+}$ & $\mathrm{O}$ & 499.3782 & 499.3801 & +3.80 & 1 \\
\hline $\mathrm{C}_{34} \mathrm{H}_{43} \mathrm{O}_{3}^{+}$ & $517^{+}-\mathrm{H}_{2} \mathrm{O}$ & 499.3207 & 499.3202 & -1.00 & 1 \\
\hline $\mathrm{C}_{27} \mathrm{H}_{39} \mathrm{O}_{5}^{+}$ & $\mathrm{K} 1^{\prime \prime}$ & 443.2792 & 443.2772 & -4.51 & 2 \\
\hline $\mathrm{C}_{27} \mathrm{H}_{37} \mathrm{O}_{4}^{+}$ & $\mathrm{T}$ & 425.2686 & 425.2663 & -5.41 & 2 \\
\hline $\mathrm{C}_{27} \mathrm{H}_{35} \mathrm{O}_{3}^{+}$ & V & 407.2581 & 407.2593 & +2.95 & 1 \\
\hline $\mathrm{C}_{26} \mathrm{H}_{37} \mathrm{O}_{2}^{+}$ & $U$ & 381.2788 & 381.2799 & +2.89 & 0,1 \\
\hline $\mathrm{C}_{17} \mathrm{H}_{23} \mathrm{O}_{4}^{+}$ & E1" & 291.1591 & 291.1601 & +3.43 & - \\
\hline $\mathrm{C}_{16} \mathrm{H}_{23} \mathrm{O}_{2}^{+}$ & $P$ & 247.1693 & 247.1678 & -6.07 & 1 \\
\hline $\mathrm{C}_{15} \mathrm{H}_{23} \mathrm{O}^{+}$ & $\mathrm{Q}$ & 219.1743 & 219.1728 & -6.84 & 1 \\
\hline $\mathrm{C}_{8} \mathrm{H}_{15} \mathrm{O}_{2}^{+}$ & $\mathrm{L}$ & 143.1067 & 143.1067 & 0.00 & 0 \\
\hline & & \multicolumn{2}{|c|}{ Average error (r.m.s.) } & 3.40 & \\
\hline & & \multicolumn{2}{|c|}{ Mean residual error } & -0.80 & \\
\hline
\end{tabular}




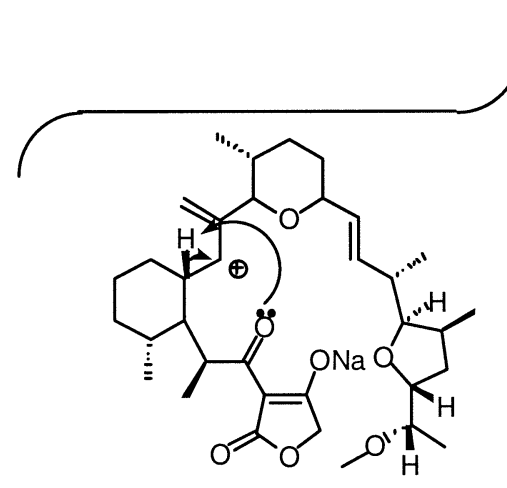

A<smiles>C1CCC1</smiles>

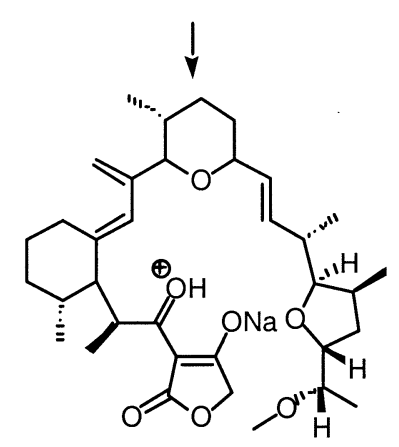

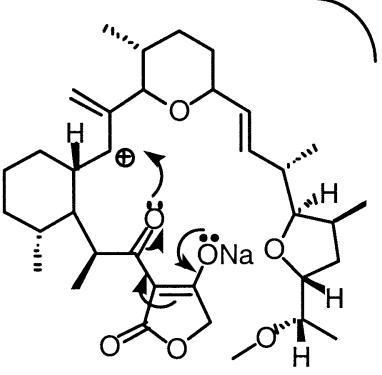

A1

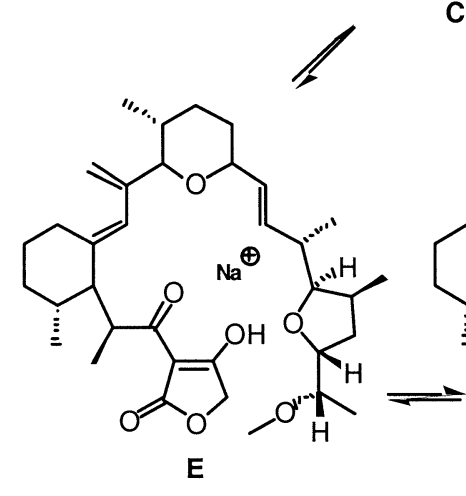

C

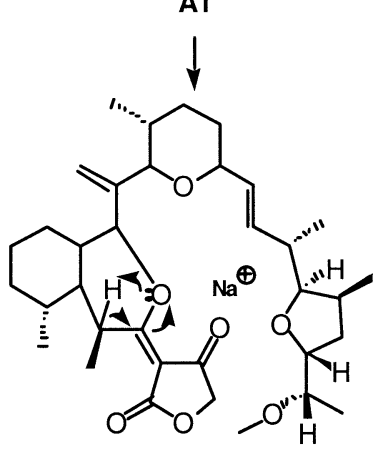

Scheme 2. Proposed mechanism for the formation of the putative intermediates (D, E, and F) derived from the carbocation $\mathbf{A}$.

(especially for the protonated ion) 40 or 80 individual scans were combined.

The MS/MS analyses of ${ }^{18} \mathrm{O}$ labeled tetronasin were performed on a quadrupole/time-of-flight (Q-TOF) mass spectrometer (Micromass, Manchester, UK). Solutions were infused by syringe pump into the ESI source at $10 \mu \mathrm{L} \mathrm{min}{ }^{-1}$. Fragmentation was performed using $\mathrm{He}$ collision gas at 30-35 normalised energy with a $\pm 1 \mathrm{~m} / \mathrm{z}$ mass selection window. The acquisition mass range was $\mathrm{m} / \mathrm{z} 100$ to 750 with 30 to 50 scans averaged to produce the spectra.

\section{Spectra Calibration and Formula Assignments}

Accurate masses for the FTICR experiments were obtained on all fragment ions (to within $5 \mathrm{ppm}$ in most cases) through a post-analysis application of a calibration obtained from the product ion spectrum of eryth- romycin A acquired under the same instrument conditions. The accuracy of the calibration is shown in the accurate-mass data tables (Tables 2 and 3). In Table 2, the rms of the ppm difference between the observed and calculated masses (mass error) is $1.93 \mathrm{ppm}$ and the mean residual error is $+0.23 \mathrm{ppm}$. In Table 3 the $\mathrm{rms}$ error is $3.40 \mathrm{ppm}$ and the mean residual is $-0.80 \mathrm{ppm}$. The rms error is indicative of the peak to peak precision of measurement, whereas the mean residual error gives in indication of any bias or inaccuracy in the overall calibration. The mean residual error should be as close to zero as possible and must be lower than the rms error for the calibration to considered reliable. With both of these spectra, the mean residual error is an order of magnitude lower than the rms error. The formula assignment of the unknown fragment ions was then achieved by using the formula of the parent ion as the atom constraints for $\mathrm{C}, \mathrm{H}$, and $\mathrm{O}$ in the elemental 


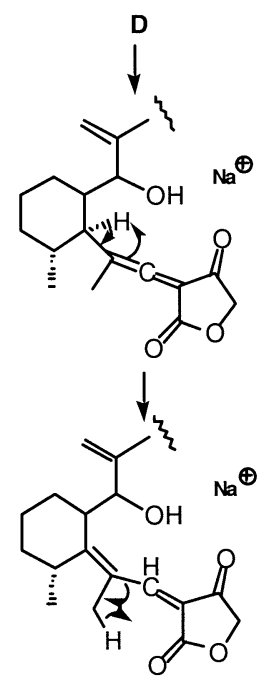

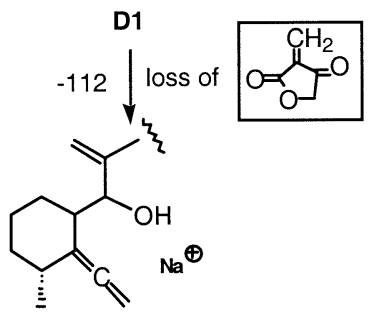

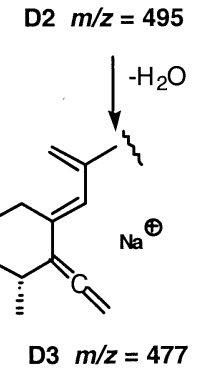

Scheme 3. The fragmentation mechanism starting from intermediate $\mathbf{D}$.

composition calculator. This usually only produced one possible formula match to within 50 ppm i.e., an order of magnitude higher than the rms error of the spectra. In the rare occasion when more than one match was obtained, logical deductions about possible structures from the $\mathrm{MS}^{\mathrm{n}}$ data were used to eliminate the extraneous formulae.

\section{Rational and Nomenclature}

In producing the schemes, we have attempted to rationalize the fragmentation by use of the simplest explanation consistent with the data obtained. We have tried to avoid invoking high-energy pathways, although some fragments can only be explained by several rearrangements. All fragmentation reactions can be considered as two electron processes with no radical ion involvement. Each fragmentation reaction results in two fragments, one of which retains the charge, the

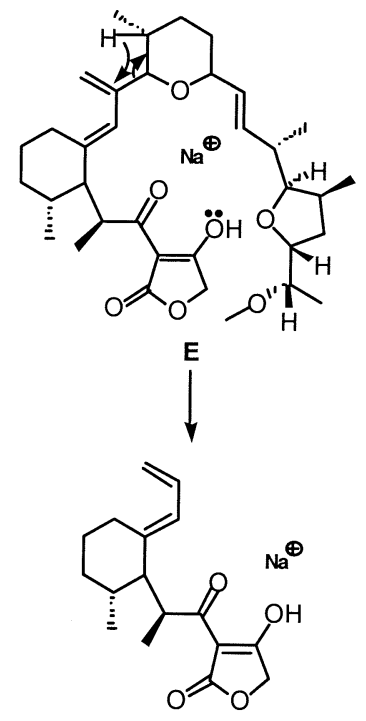

E1 $m / z=313$

and

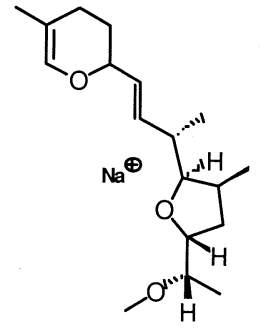

E2 $m / z=317$
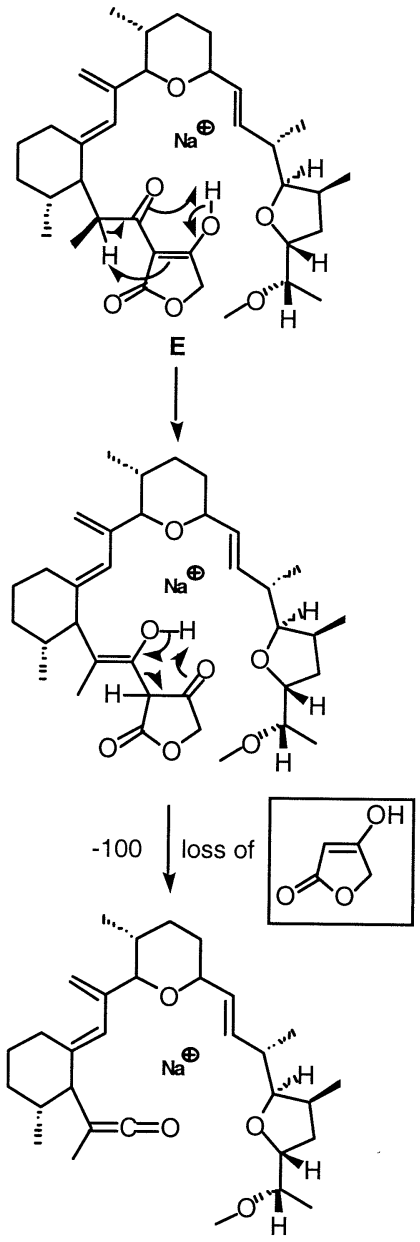

E3 $m / z=507$

Scheme 4. The fragmentation mechanisms starting from intermediate $\mathbf{E}$.

other being lost as a neutral. In some cases, the charge can be retained by either fragment producing two sub-fragmentation routes from the same precursor ion. For clarity we have adopted the following fragment ion identification scheme. Structures C, D, E, and F are possible forms of the ion at $m / z=607$ and are responsible for the majority of the ions observed. For example, the fragment ions E1, E2, and E3 are subfragments of the Isomer E. For the fragmentation of the protonated ion, many of the routes followed were analogous to those observed for the sodium salt, and in these cases the fragments were identified by a double inverted coma after the letter.

\section{Results and Discussion}

The ESI/MS spectrum of tetronasin shows the presence of several peaks, corresponding for example, to mono-, disodiated, and potassiated peaks (Figure 2a and Table 1). At low fragmentation energy, the MS/MS spectra of protonated tetronasin sodium salt $[(\mathrm{M}-\mathrm{H}+\mathrm{Na})+\mathrm{H}]^{+}$ $(m / z=625)$ and the protonated tetronasin $[(\mathrm{M}+\mathrm{H})]^{+}$ 

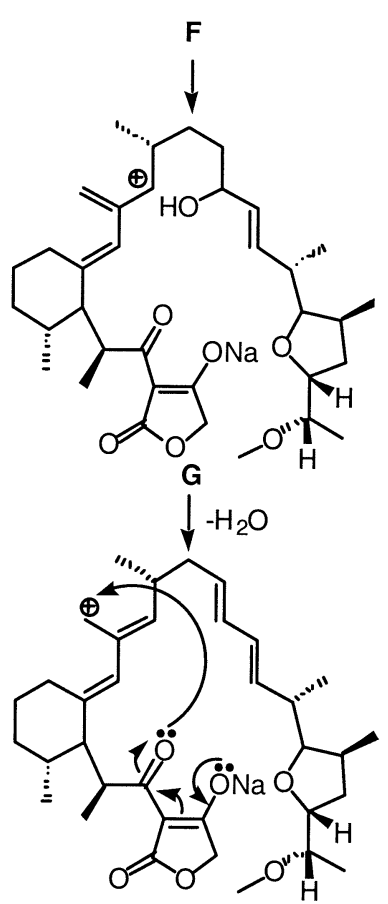

G1 $m / z=589$
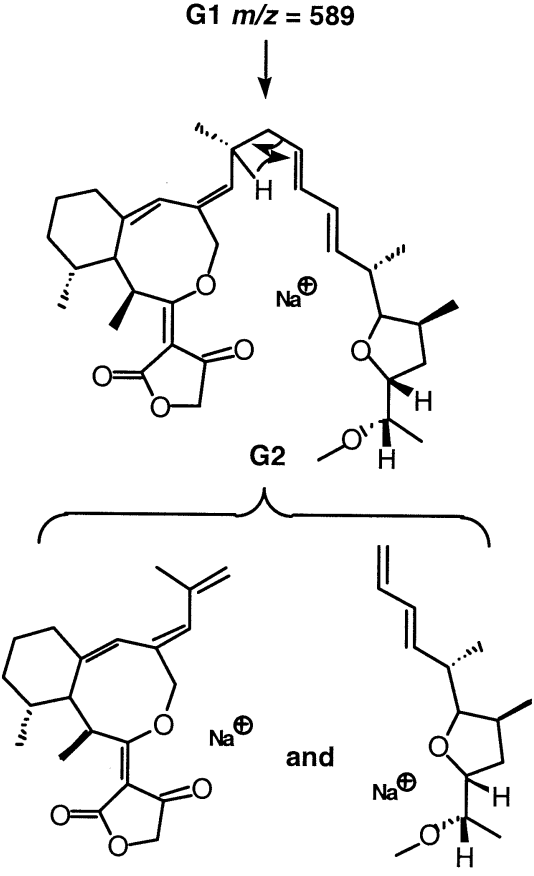

G3 $m / z=365$

G4 $m / z=247$

Scheme 5. First fragmentation mechanism starting from intermediate $\mathbf{F}$.

$(\mathrm{m} / \mathrm{z}=603)$ only showed a peak at $\mathrm{m} / \mathrm{z}=607$ and $\mathrm{m} / \mathrm{z}=$ 585 , respectively (Figures $2 b$ and $c$ ). These fragmentations derive from a loss of a water molecule. The results obtained suggest that the first water loss occurs from the hydroxyl group at C28. We propose that this first loss can happen via two different mechanisms. The MS/MS spectrum of the deuterated tetronasin (Figure 3a) shows that one mechanism implicates a charge remote neutral loss of water by a 1,4-elimination (loss of $\mathrm{DOH}$ ) as the minor route (Figure $3 \mathrm{~b}$ ) [15]. The second mechanism, the major route, requires that protonation (or deuteration) of the hydroxyl group at C28 occurs leading to the loss of $\mathrm{D}_{2} \mathrm{O}$ and formation of a allylic carbocation A (Figure $3 \mathrm{~b}$ ), that shows good relative stability through resonance.

The ESI-MS spectrum of the ${ }^{18} \mathrm{O}$ labeled tetronasin showed ions corresponding to the incorporation of ${ }^{18} \mathrm{O}$ $\left(\mathrm{m} / \mathrm{z}=627\right.$ with one ${ }^{18} \mathrm{O}$ and $\mathrm{m} / \mathrm{z}=629$ with two $\left.{ }^{18} \mathrm{O}\right)$. Dissociation of both of these ions showed only a loss of water $\left(\mathrm{H}_{2} \mathrm{O}\right)$ forming the fragments corresponding to $m / z=609$ and $m / z=611$ (Table 2), respectively. This means that the loss of the first water from the hydroxyl at $\mathrm{C} 28$ contains no ${ }^{18} \mathrm{O}$, suggesting that the incorporation of ${ }^{18} \mathrm{O}$ is in the tetronic moiety or carbonyl $\mathrm{C} 5$ as expected.

Increasing the collision energies had little effect on the MS/MS spectra of either the protonated sodium salt $[(\mathrm{M}-\mathrm{H}+\mathrm{Na})+\mathrm{H}]^{+}$or protonated molecule $[(\mathrm{M}+$ $\mathrm{H})]^{+}$. An additional collision stage $\left(\mathrm{MS}^{3}\right)$ was required to produce a full series of fragment ions. This behavior is probably indicative of the stability of the quasi-cyclic conformation of the tetronasin. The $\mathrm{MS}^{3}$ spectra obtained for the protonated sodium salt $\left(625^{+} \rightarrow 607^{+} \rightarrow\right.$ fragments) and protonated molecule $\left(603^{+} \rightarrow 585^{+} \rightarrow\right.$ fragments), respectively, can be seen in Figure 4. An overview of the different routes of these fragmentation pathways is shown in Scheme 1. The mass accuracy data is contained in Tables 2 and 3.

The fragmentation observed in the $\mathrm{MS}^{3}$ spectrum of 607 arises from carbocation A, as previously explained. We propose that the observed complex neutral eliminations arise from different mechanisms, such as $\beta$-eliminations and hydrogen shifts. Some of the fragmentations observed on the $\mathrm{MS}^{3}$ spectrum of 607 don't occur in the $\mathrm{MS}^{3}$ spectrum of 585 , probably due to the presence of sodium. The ${ }^{18} \mathrm{O}$ labeling experiment, in particular the MS/MS spectrum of the ion at $m / z=611$ (with two incorporated ${ }^{18} \mathrm{O}$ atoms), supports the proposed structures observed on $\mathrm{MS}^{3}$ spectrum of 607.

As an initial example, migration of the proton at $\mathrm{C} 12$ of the stable conjugated resonance form A1 (Scheme 2) to the carbonyl at $\mathrm{C} 5$, assisted by the lone pair of electrons from oxygen C5, can give the species C (Scheme 2) in which the carbonyl at $\mathrm{C} 5$ gets protonated. Structure $\mathbf{C}$ may then be in equilibrium with two different forms, $\mathbf{E}$ and $\mathbf{F}$. The carbonyl at C5 can alternatively attack the form A1 (Scheme 2) (this process being initiated by one of the lone pair of electrons of the oxygen at C3), as in a Lewis acid-base reaction [16, 17], resulting in the formation of a stable six membered ring in which the charge is now attributable to sodium (see Structure A2, Scheme 2). The migration of the proton at C6 to the heterocyclic oxygen followed by opening of the six membered ring at the bond $\mathrm{C} 5-\mathrm{O}$ produces the allene D. Structures D, E, and F (Scheme 2 ) are putative intermediates for the mechanisms discussed in the following section. It is not possible to explain subse- 


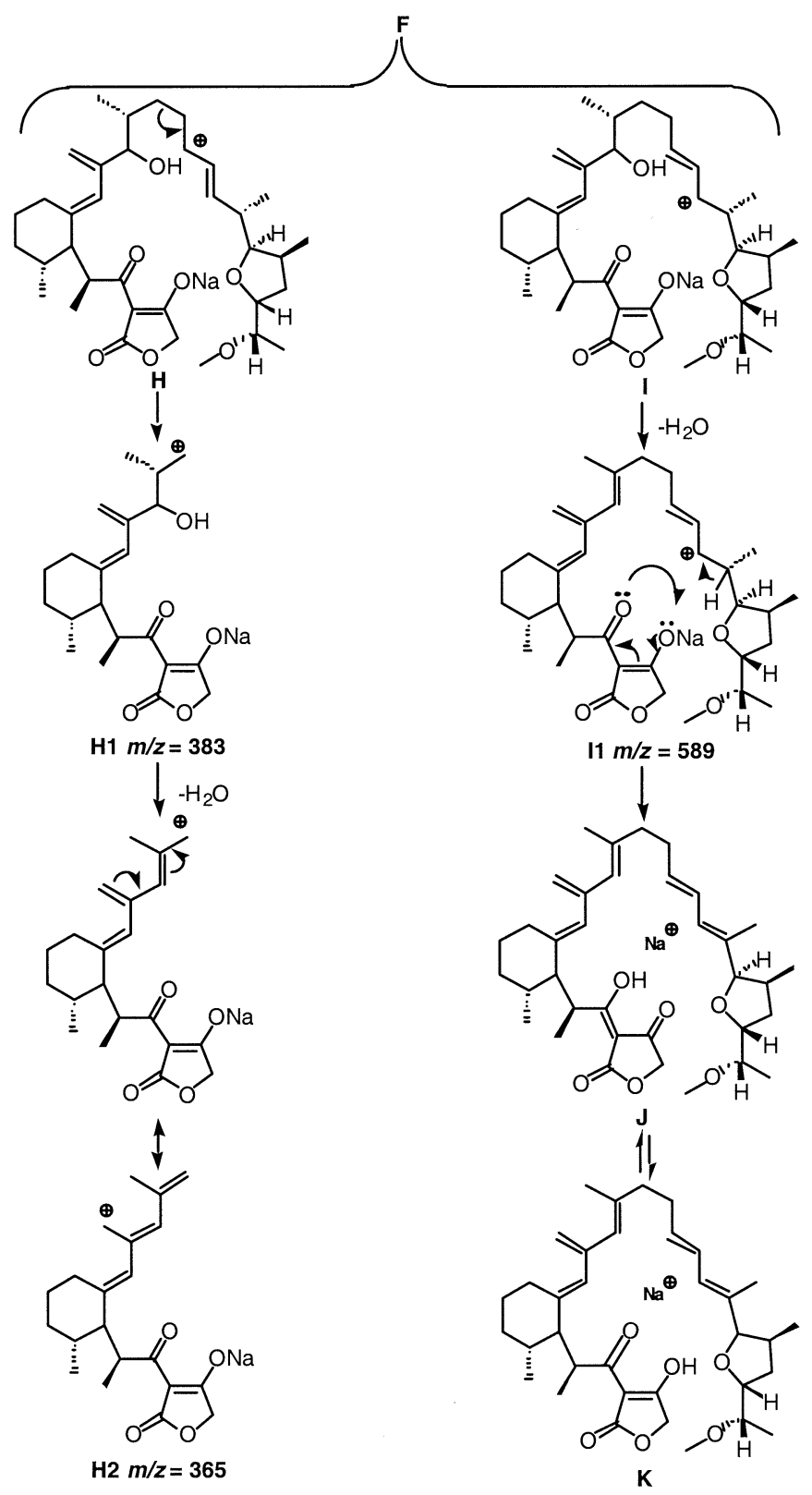

Scheme 6. Second and third fragmentation mechanisms starting from intermediate F.

quent fragmentation without the existence of these intermediates.

We propose that the fragments $\mathbf{D} 2(\mathrm{~m} / \mathrm{z}=495)$ and D3 $(m / z=477)$ derive from the same route (Scheme 3) with $\mathbf{D}$ being the precursor. This route may be explained by an initial 1,3-hydrogen shift of the proton at C7 to C5 with the formation of the diene D1, that then gives the allene $\mathbf{D} 2(\mathrm{~m} / \mathrm{z}=495)$ via a simple neutral elimination of the 3-methylene-furan-2,4-dione unit. The sodiated ion $\mathbf{D} 2$ can then undergo a charge-remote neutral loss of one molecule of water leading to $\mathbf{D} 3(\mathrm{~m} / \mathrm{z}$ $=477)$. The MS/MS spectrum of the ion at $\mathrm{m} / \mathrm{z}=611$ (with two incorporated ${ }^{18} \mathrm{O}$ atoms) shows the presence of peaks at $m / z=497$, suggesting that the ${ }^{18} \mathrm{O}$ atoms where possibly exchanged at the carbonyl at C5 and one of carbonyls of the tetronic moiety. Therefore, $\mathrm{m} / \mathrm{z}=497$ corresponds to the ion $\mathbf{D} 2$ with one ${ }^{18} \mathrm{O}$ remaining at $\mathrm{C} 13$ after the rearrangement.

Scheme 4 shows the two additional fragmentation routes that may explain the formation of the fragments E1 $(m / z=313)$, E2 $(m / z=317)$, and E3 $(m / z=507)$. Structures E1 and E2 may derive from a $\beta$-elimination with cleavage at the bond C14-15. The sodium cation can be chelated to both of the resulting neutral fragments leading to the sodiated ions E1 or E2. The ${ }^{18} \mathrm{O}$ labeling experiment shows only a peak at $\mathrm{m} / \mathrm{z}=317$ corresponding to the coincidence of E1 with two exchanged oxygens and E2 with no exchanged oxygens. 


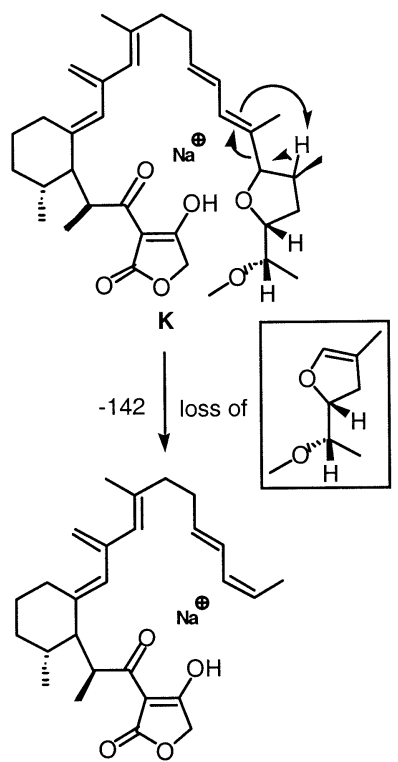

K1 $m / z=447$
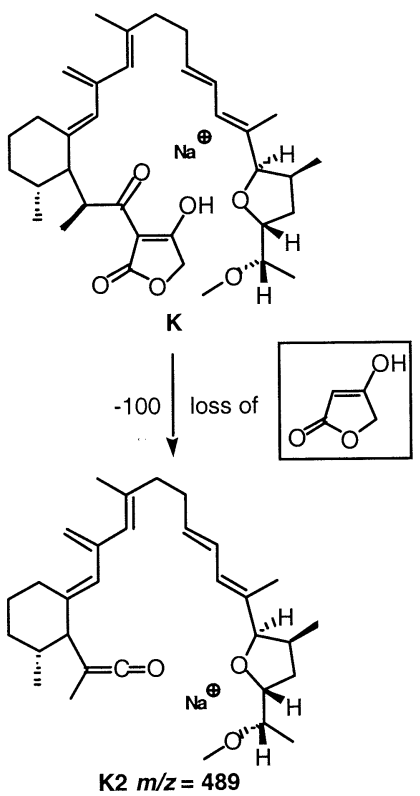

Scheme 7. The fragmentation mechanisms starting from inter-

The intermediate $\mathbf{E}$ can alternatively undergo a simple neutral loss of mass 100 (Scheme 4), corresponding to the tetronic acid unit, to form the ketene E3. This loss occurs as mass 102 in the ${ }^{18} \mathrm{O}$ labeling experiments which is in agreement with the proposed mechanisms.

The intermediate $\mathbf{F}$, in which the oxygen of the pyran ring is protonated, may dissociate by three different routes (Schemes $\mathbf{5}$ and $\mathbf{6}$ ). The first one implies that the resonance form $\mathbf{G}$, in which the ring is opened at the bond $\mathrm{C} 15-\mathrm{O}$, can undergo a neutral loss of one molecule of water with the formation G1 (Scheme 5), one of the possible fragments corresponding to $\mathrm{m} / \mathrm{z}=589 \mathrm{(m} / \mathrm{z}$ $=593$ on ${ }^{18} \mathrm{O}$ labeling experiment). An eight membered ring (see G2, Scheme 5) can be formed by the attack of a lone pair of electrons of the oxygen of the carbonyl at C5, to the carbocation G1 as described for A1 (Scheme 2). A 1,3-hydrogen shift from the proton at $\mathrm{C} 16$ to $\mathrm{C} 18$ of $\mathbf{G} 2$ followed by a cleavage at the bond C17-18 may produce the ions G3 $(\mathrm{m} / \mathrm{z}=365)$ and $\mathbf{G} 4(\mathrm{~m} / \mathrm{z}=247)$. In the ${ }^{18} \mathrm{O}$ labeling experiment, $\mathrm{m} / \mathrm{z}=369$ and $\mathrm{m} / \mathrm{z}=247$ were observed, corresponding, respectively, to G3 with mediate $\mathbf{K}$.

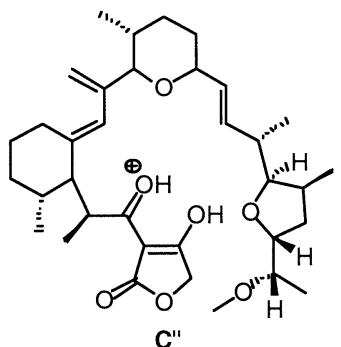

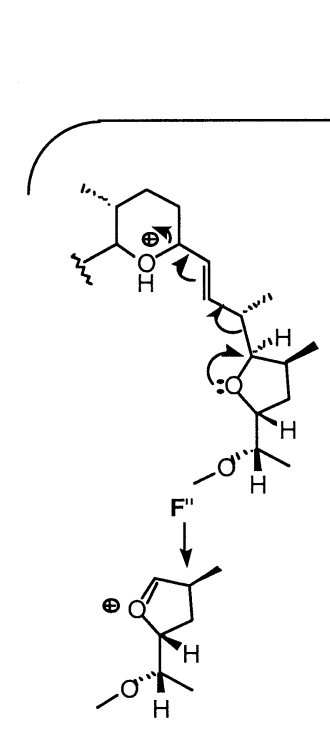

$\mathrm{L} m / z=143$

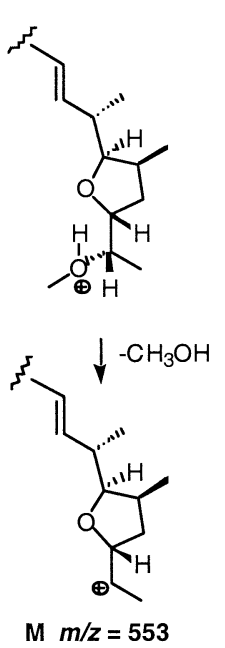

$M m / z=553$

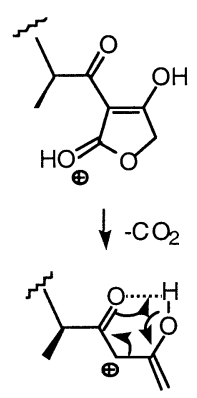

$\mathrm{N} m / z=541$

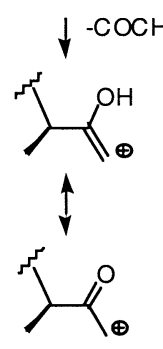

$0 \mathrm{~m} / z=499$

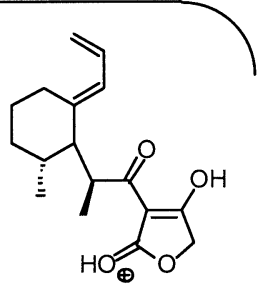

E1" $m / z=291$

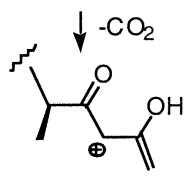

$P m / z=247$

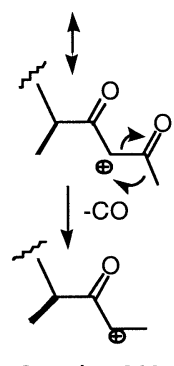

$Q m / z=219$

Scheme 8. The fragmentation mechanisms starting from intermediate $\mathbf{C}^{\prime \prime}$. 

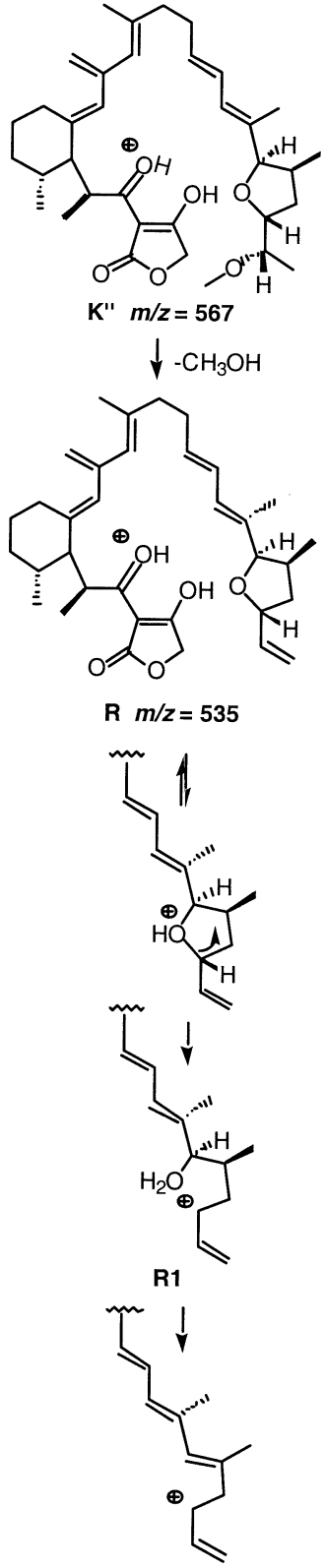

S $m / z=517$

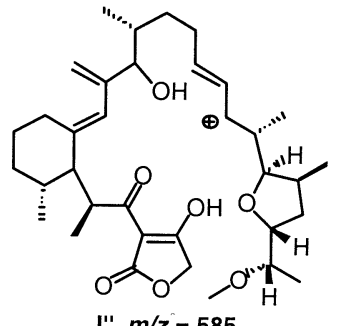

l' $m / z=585$
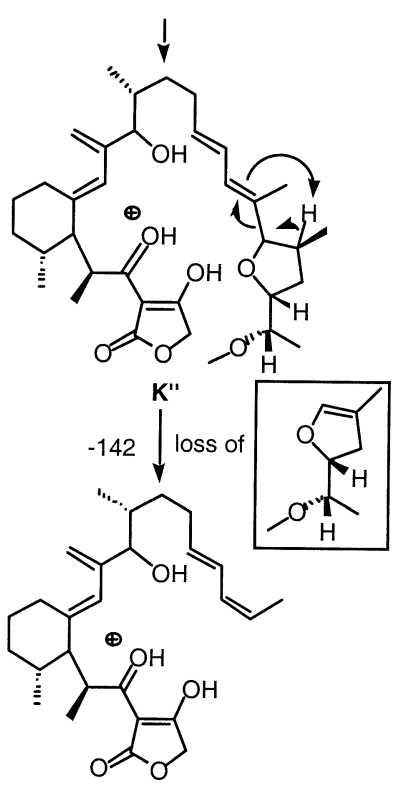

$\mathrm{K} 1 " \mathrm{~m} / \mathrm{z}=\mathbf{4 4 3}$

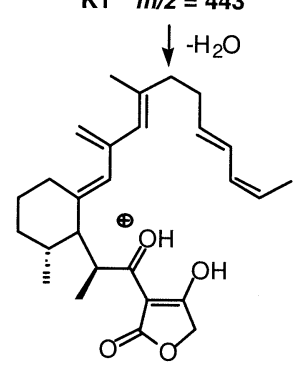

$\mathrm{T} m / z=425$

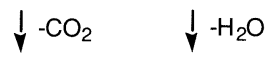

U $m / z=381 \quad$ V $m / z=407$

Scheme 9. The fragmentation mechanisms starting from intermediates I" and $\mathbf{K}^{\prime \prime}$.

two exchanged oxygens and G4 with no exchanged oxygens.

Another possible resonance form of $\mathbf{F}$ is Structure $\mathbf{H}$ (Scheme 6). In this intermediate the ring is opened at the bond C19-O. Fragmentation at the bond C17-18 leads to the carbocation $\mathbf{H 1}(\mathrm{m} / \mathrm{z}=383)$, that later can lose water producing $\mathbf{H} \mathbf{2}(\mathrm{m} / \mathrm{z}=365)$. The Structure $\mathbf{H} \mathbf{2}$ shows good relative stability by resonance. In the ${ }^{18} \mathrm{O}$ labeling experiment, the ions corresponding to $\mathrm{m} / \mathrm{z}=$ 387 (H1 with two exchanged oxygens) and $\mathrm{m} / \mathrm{z}=369$ (H2 with two exchanged oxygens) were observed.

The carbocation I (Scheme 6), another resonance form of $\mathbf{F}$, may lose a molecule of water with the

formation of I1 $(m / z=589)$. Migration of the proton at $\mathrm{C} 22$ to the carbonyl at C5 produces J. The Structure K (a resonance form of $\mathbf{J}$ ) can undergo a neutral elimination of the dihydro-furan unit as seen in Scheme $\mathbf{7}$ giving K1 $(\mathrm{m} / \mathrm{z}=447)$. As already observed for the intermediate $\mathbf{E}$, $\mathbf{K}$ (Scheme 4) may also lose the tetronic acid unit, producing the sodiated ion $\mathbf{K} 2(\mathrm{~m} / \mathrm{z}=489)$. In the ${ }^{18} \mathrm{O}$ labeling experiment, the ions corresponding to $\mathrm{m} / \mathrm{z}=$ 451 (K1 with two exchanged oxygens) and $\mathrm{m} / z=369$ (K2 with one exchanged oxygen) were observed.

The fragmentations observed in the $\mathrm{MS}^{3}$ spectrum of $\mathrm{m} / \mathrm{z} 585$ (Figure $4 \mathrm{~b}$ ) follow a similar mechanism to that which was observed in the $\mathrm{MS}^{3}$ spectrum of $\mathrm{m} / \mathrm{z} 607$, however, due to extra proton, losses of $\mathrm{CO}_{2}, \mathrm{CH}_{3} \mathrm{OH}$, $\mathrm{H}_{2} \mathrm{O}$ and other small neutrals are additionally observed. As described for the sodiated tetronasin spectrum, an ${ }^{18} \mathrm{O}$ experiment was used to support the proposed mechanisms. In this part of the discussion the ${ }^{18} \mathrm{O}$ labeling experiment corresponds to MS/MS of the ion at $m / z=589$. All the corresponding ${ }^{18} \mathrm{O}$ labeled fragments are listed in Table 3.

To explain some of the fragment ions in the $\mathrm{MS}^{3}$ spectrum of $\mathrm{m} / \mathrm{z} 585$, we propose that the ion assumes the putative Structure C' (Scheme 8). This molecule can then be the origin of several different fragment ions by four simple mechanisms. Assuming that the $\mathrm{C}^{\prime \prime}$ form is protonated at the oxygen of the pyran ring $\mathbf{F}^{\prime \prime}$, it can later undergo a concerted elimination that is initiated by one of the lone pairs of the oxygen from the furan ring, leading to the formation of the cation $\mathbf{L}(\mathrm{m} / \mathrm{z}=$ 143). The Structure $C^{\prime \prime}$ may also be in equilibrium with a form in which the protonation occurs in the methoxy group inducing an easy loss of methanol with the production of the carbocation $\mathbf{M}(m / z=553)$. If $\mathbf{C}^{\prime \prime}$ is in equilibrium with a form in which the tetronic moiety is protonated, a loss of carbon dioxide may occur giving $\mathbf{N}$ $(\mathrm{m} / \mathrm{z}=541)$, that is observed at very low intensity. The later fragment may then lose $\mathrm{COCH}_{2}$ by a pericyclic elimination mechanism leading to the fragment $\mathbf{O}(\mathrm{m} / \mathrm{z}$ $=499$ ). For the fourth mechanism we propose that the protonated species $C^{\prime \prime}$ undergoes a $\beta$-elimination at C14-15 with the formation of a fragment E1" $(\mathrm{m} / \mathrm{z}=$ 291), that by loss of $\mathrm{CO}_{2}$ gives the fragment $\mathbf{P}(\mathrm{m} / \mathrm{z}=$ 247). The diketide resonance form of $\mathbf{P}$ may then lose $\mathrm{CO}$ with the formation of the fragment $\mathbf{Q}(\mathrm{m} / \mathrm{z}=219)$.

Two additional mechanisms that may explain the rest of the fragments derived from $\mathrm{m} / \mathrm{z} 585$ are described on Scheme 9. One involves a charge-remote neutral elimination of methanol from $\mathbf{K}^{\prime \prime}(\mathrm{m} / \mathrm{z}=567)$ giving fragment $\mathbf{R}(m / z=535)$. If the oxygen from the furan ring of $\mathbf{R}$ is protonated, this may then open with the formation of the carbocation R1 followed by loss of water giving fragment $\mathbf{S}(\mathrm{m} / \mathrm{z}=517)$ that is stabilized by resonance. Structure $\mathbf{S}$ may also correspond to a loss of water from the tetronic moiety of $\mathbf{R}$, which explains the peaks observed in the ${ }^{18} \mathrm{O}$ experiment $(\mathrm{m} / \mathrm{z}=519$ with one exchanged oxygen and $\mathrm{m} / \mathrm{z}=521$ with two exchanged oxygens).

The second mechanism leads to the formation of $\mathbf{K 1} \mathbf{1}^{\prime \prime}$ 
$(m / z=443)$, in a similar manner to what was observed in the $\mathrm{MS}^{3}$ spectrum of the sodiated tetronasin, for the intermediate I. Fragment T $(m / z=425)$ results from a loss of water and can subsequently eliminate both $\mathrm{CO}_{2}$ and water to produce the fragments $\mathbf{U}(\mathrm{m} / \mathrm{z}=381)$ and V $(m / z=407)$, respectively.

\section{Conclusions}

Complete fragmentation pathways are proposed for protonated tetronasin and the protonated tetronasin sodium salt. The formulae of the fragment ions are confirmed by accurate-mass analysis (see Tables 1, 2, and 3) to within 5 ppm in most cases (with a $1.93 \mathrm{ppm}$ r.m.s. error for $\mathrm{MS}^{3}$ of 607 and a 3.4 ppm r.m.s. error in the $\mathrm{MS}^{3}$ of 585). The larger average error in the analysis of the protonated ion is probably the result of fewer ions being measured, resulting in the lower signal-tonoise ratio observed in the spectrum. The analysis performed in deuterated media clearly shows the two possible routes for the first water loss. The ${ }^{18} \mathrm{O}$ labeling experiments also provide useful data to support some of the proposed mechanisms.

The results presented will be of significant use for future identification of tetronasin metabolites and biosynthetically generated derivatives.

\section{Acknowledgments}

The authors thank Sarah Maslen from the Mass Spectrometry Section of the Department of Chemistry, University of Cambridge, for the Q-TOF MS/MS analysis. This research was supported by the Biotechnology and Biological Sciences Research Council (London, UK), the Unilever Safety and Environmental Assurance Center (Bedford, UK) and the Fundação de Amparo a Pesquisa do Estado (São Paulo, Brazil).

\section{References}

1. Westley, J. W., Ed.; Polyether Antibiotics; Vols I and II; Marcel Dekker: New York, NY, 1982.

2. Shen, J.; Brodbelt, J. S. Characterization of Ionophore-Metal Complexes by Infrared Multiphoton Photodissociation and Collision Activated Dissociation in a Quadrupole Ion Trap Mass Spectrometer. Analyst 2000, 125, 641-650.

3. (a) Davies, D. H., Norris G. L. F., GB Patent 2,027,013/1980; (b) Newbold, C. J.; Wallace, R. J.; Watt, N. D.; Richardson, A. J. Effect of Novel Ionophore Tetronasin (ICI-139603) on Ruminal Microorganisms. Appl. Environ. Microbiol. 1988, 54, 544-547.

4. Riddel, F. G. Ionophore Antibiotics. Chem. Brit. 1992, 28, 533-537.
5. (a) Elliot, C. T.; Kennedy, D. G.; McCaughey, W. J. Methods for the Detection of Polyether Ionophore Residues in Poultry. Analyst 1998, 123, 45-56; (b) Matabudul, D. K.; Conway, B.; Lumley, I. D. A Rapid Method for the Determination of Lasalocid in Animal Tissues and Eggs by High Performance Liquid Chromatography with Fluorescence Detection and Confirmation by LC-MS-MS. Analyst 2000, 125, 2196-2200; (c) Harris, J. A.; Russel, C. A. L.; Wilkins, J. P. G. The Characterization of Polyether Ionophore Veterinary Drugs by HPLCEelectrospray MS. Analyst 1998, 123, 2625-2628; (d) Matabudul, D. K.; Lumley, I. D.; Points, J. S. The Determination of 5 Anticoccidial Drugs (Nicarbazin, Lasalocid, Monensin, Salinomycin, and Narasin) in Animal Livers and Eggs by Liquid Chromatography Linked with Tandem Mass Spectrometry (LC-MS-MS). Analyst 2002, 127, 760-768.

6. (a) Lopes, N. P.; Stark, C. B. W.; Hong, H.; Gates, P. J.; Staunton, J. Fragmentation Studies on Monensin A and B by Accurate-Mass Electrospray Tandem Mass Spectrometry. Rapid Commun. Mass Spectrom. 2002, 16, 414-420; (b) Lopes, N. P.; Stark, C. B. W.; Gates, P. J.; Staunton, J. Fragmentation Studies on Monensin A by Sequential Electrospray Mass Spectrometry. Analyst 2002, 127, 503-506.

7. Lopes, N. P.; Gates, P. J.; Wilkins, J. P. G.; Staunton, J. Fragmentation Studies on Lasalocid Acid by Accurate Mass Electrospray Mass Spectrometry. Analyst 2002, 127, 1224-1227.

8. Gates, P. J.; Lopes, N. P.; Hong, H.; Wilkins, J. P. G.; Staunton, J. Fragmentation Studies on Salinomycin and Narasin by Accurate-Mass Electrospray Sequential Mass Spectrometry, unpublished.

9. Davies, D. H.; Snape, E. W.; Suter, P. J. Structure of Antibiotic M139603; X-Ray Crystal Structure of 4-Bromo-3,5-dinitrobenzoyl Derivative. J. Chem. Soc. Chem. Commun. 1981, 1073-1074.

10. Martinek, T.; Riddel, F. G.; Rutherford, T. J.; Sareth, S.; Weller, C. T. The Structure of the Ionophore Antibiotic Na-tetronasin (M139603) in Solution. Chem. Commun. 1998, 17, 1893-1894.

11. Gross, M. L. Tandem Mass Spectrometric Strategies for Determining Structure of Biologically Interesting Molecules. Acc. Chem. Res. 1994, 27, 361-369.

12. Stark, C. B. W.; Lopes, N. P.; Fonseca, T.; Gates, P. J. The Effect of Ruthenium (III) Chloride on the Formation of Protonated Parent Ions in Electrospray Mass Spectrometry. Chem. Commun. 2003, 21, 2732-2733.

13. Roddis, M.; Gates, P.; Roddis, Y.; Staunton, J. Structural Elucidation Studies on 14- and 16-Membered Macrolide Aglycones by Accurate-Mass Electrospray Sequential Mass Spectrometry. J. Am. Soc. Mass Spectrom. 2002, 13, 862-874.

14. Less, S. Biosynthetic Studies on Tetronasin; Ph.D. Thesis, University of Cambridge, 1996, pp 87-88.

15. Hill, R. K.; Bock, M. G. Stereochemistry of 1,4-Conjugate Elimination Reactions. J. Am. Chem. Soc. 1978, 100, 637-638.

16. Carey, F. A.; Sundberg, R. J. Advanced Organic Chemistry. Part B: Reactions and Synthesis, 3rd ed; Plenum Press: New York, NY, 1990; p 509.

17. March, J. Advanced Organic Chemistry, Reactions, Mechanisms, and Structure, 3rd ed; John Wiley and Sons: New York, NY, 1985, pp 150, 745. 